Survey

\section{Emotional intelligence: enhancing value-based practice and compassionate care in nursing}

10.1136/eb-2014-101733

\section{Estelle Codier}

School of Nursing and Dental Hygiene, University of Hawaii, Manoa, Honolulu, USA

Correspondence to: Professor Estelle Codier, School of Nursing and Dental Hygiene, University of Hawaii, Manoa, Honolulu, USA; codier@hawaii.edu

Commentary on: Rankin B. Emotional intelligence: enhancing values-based practice and compassionate care in nursing. J Adv Nurs 2013;69:2717-25.

\section{Implications for practice and research}

- Nursing school admission criteria that screen for emotional competency could result in a nursing workforce better equipped to provide care that is human centred as well as instrumental.

- Nurses selected and educated for emotional capability could create a workforce with greater resilience and retention.

- This study provides a foundation for further research on emotional intelligence measures and successful graduation from nursing school as well as postgraduation success.

\section{Context}

Nursing school admission officers and educators alike have expressed growing interest in criteria for admission to nursing school beyond those traditionally used (standardised testing scores and previous academic achievement). This interest has grown in a care climate where a greater need for human-centred caring (the patient's experience of being cared for) over and above instrumental caring (nursing care activities) has been identified. ${ }^{1}$ Findings from this longitudinal study by Rankin demonstrated a correlation between emotional intelligence (EI) measures at admission to nursing school with academic retention as well as clinical and academic performance during the first year of nursing school.

\section{Methods}

This study tested the hypothesis that EI predicts first year nursing school programme outcomes that included retention and clinical as well as academic performance. A sample of 178 predominantly white female students starting a pre-registration nursing course in one UK university completed a self-report EI survey. Demographic data was gathered as well as a measure of prior academic attainment based on the Scottish Credit and Qualifications Framework. Retention was measured by enrolment in the second semester. Practice performance was measured on a 1-4 scale for each clinical outcome measured. Academic performance was measured using the mean score for all first year programme assignments.

\section{Findings}

Of the 178 students enrolled in the study, 116 progressed to the second year of the nursing programme. In that group, age as well as EI were predictors of progression to the second academic year (age $r=0.27, N=178$, $\mathrm{p}<0.001$; total EI score $\mathrm{r}=0.30, \mathrm{~N}=178, \mathrm{p}<0.001$ ). Only the 116 who progressed were evaluated for the relationship between EI and clinical performance. Among them, the relationship proved significant, particularly the 'perception of emotions' $(\mathrm{r}=0.24, \mathrm{~N}=138, \mathrm{p}<0.05)$ and 'managing own emotions' $(\mathrm{r}=0.18, \mathrm{~N}=138, \mathrm{p}<0.05)$ subscores. Academic performance on the course also correlated significantly with the total EI score $(r=0.16$, $\mathrm{N}=138, \mathrm{p}<0.05$ ). These findings are particularly important because there was no relationship between students' prior academic achievement and measured EI.

\section{Commentary}

The importance of this study lies in the substantial evidence it provides for the predictive relationship between measured EI and first year nursing school programme outcomes (retention, clinical performance and academic performance). The relationship between clinical performance and measured EI is particularly significant. These findings validate previous research among nurses postgraduation, in whom measured EI correlated with both level of clinical performance and retention. ${ }^{2} 3$

In addition, the study supports the use of the four-branch model of EI that operationalises EI as the ability to correctly identify emotions, to use them in reasoning and to understand as well as manage them. ${ }^{4}$ This model focuses on EI as an ability, as opposed to other models that conceptualise it as a function of personality, or as a combination of ability and personality attributes. This is an important issue for nursing EI research, as EI models that overlap with existing values and personality constructs undermine the face validity of EI as a distinct concept. The findings of this study also provide the basis for incorporating EI outcomes into those required for both clinical performance in nursing school and in clinical practice after graduation. This could provide an entirely new approach to operationalising psycho/social nursing and human-centred caring.

In addition to demographic factors that limited the generalisability of the study (the sample population was predominantly Caucasian, female European Union residents), the use of an EI self-report measure also created limitations. Self-report instrumentation is solely dependent on an individual's ability to self-assess correctly and report impartially. Further research using an EI instrument, such as the MSCEIT, V.2 (Mayer-Salovey-Caruso Emotional Intelligence Test, V.2), an instrument with rigorous validity and reliability which requires the performance of emotional tasks, would provide important comparison data.

Competing interests None.

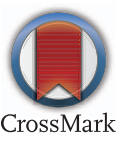

\section{References}

1. Bradley P, Falk-Rafael A. Instrumental care and human-centered caring: rhetoric and lived reality. Adv Nurs Sci 2011;34:297-314.

2. Codier E, Kamikawa C, Kooker BM, et al. Emotional intelligence: performance and retention. Nurs Adm Q 2009;33:310-16.

3. Codier E, Kooker BM, Shoultz J. Measuring the emotional intelligence of clinical staff nurses: an approach for improving the clinical care environment. Nurs Adm Q 2008;32:8-14.

4. Mayer JD, Salovey P, Caruso DR. Emotional intelligence: new ability or ecclectic traits? Am Psychol 2008;63:503-17. 